Research Article

\title{
Breastfeeding practices in children under 6 months of age: a community based study in urban field practice area of a medical college in central Gujarat, India
}

\author{
Kajal Davara*, Paragkumar Chavda, Chandresh Pandya, Dipak Solanki
}

Department of Community Medicine, GMERS Medical College, Gotri, Vadodara, Gujarat, India

Received: 29 March 2016

Revised: 01 April 2016

Accepted: 05 April 2016

*Correspondence:

Dr. Kajal Davara,

E-mail: kbdavara23@gmail.com

Copyright: () the author(s), publisher and licensee Medip Academy. This is an open-access article distributed under the terms of the Creative Commons Attribution Non-Commercial License, which permits unrestricted non-commercial use, distribution, and reproduction in any medium, provided the original work is properly cited.

\section{ABSTRACT}

Background: Early and exclusive breastfeeding (EBF) is recognized as one of the most effective interventions for child survival particularly to address childhood morbidity and mortality. In spite of the countless benefits, the prevalence of EBF in India, according to the NFHS-3 (2005-2006), at 6 months was only 46.4\%. Constraints to EBF are breastfeeding problems, delivery by caesarean section, perceived or real breast milk insufficiency, resumption of official work by the mother, and cultural practices. The objective of the study was to assess current breastfeeding practices of mothers having children less than 6 months of age and to assess the correct positioning, attachment and effective suckling as practiced by these mothers.

Methods: An observational, cross-sectional study was done in urban field practice area of a medical college in Central Gujarat from August 2015 to September 2015. Thirty two mother-infant units were observed for baby's position, attachment and effective suckling using standard IMNCI guideline. Data thus collected were analysed using Microsoft Excel.

Results: Out of the criteria for correct attachment, only two children fulfilled all 4 criteria which were classified as having 'good attachment'. The assessment for proper positioning revealed that only around $13 \%$ infants fulfilled all 4 criteria for good positioning. Almost half of the infants were suckling effectively.

Conclusions: Based on the findings of the study, it is recommended that each mother should be observed for mother's and infant's positioning and attachment at the onset of breastfeeding and if needed given counselling on correct breastfeeding practices.

Keywords: Breastfeeding practices, Positioning, Attachment (latch-on), IMNCI

\section{INTRODUCTION}

Breastfeeding during early childhood is vital for survival, growth and development. It confers from physiological to psychological benefits to both child and mother. Breastfeeding also helps to protect children against a variety of acute and chronic disorders. The World Health Organization recommends exclusive breastfeeding for the first 6 months of life with early initiation and continuation of breastfeeding for 2 years or more together with nutritionally-adequate, safe, age-appropriate complementary feeding starting at 6 months. ${ }^{1}$

Breast feeding is a universal phenomenon in India, but breast feeding practices are far from optimal because they are influenced by socioeconomic factors, cultural background, psychological status, religious values, illiteracy, ignorance, lack of access to antenatal and 
postnatal care, inadequate training, knowledge and skills of breast feeding. ${ }^{2}$ Proper positioning of mother and baby and attachment of baby to the mother's breast is required for effective breastfeeding. The IMNCI strategy recommends systematic assessment of breastfeeding and emphasizes counselling of the mother on proper positioning and attachment of infant to the breast. ${ }^{3}$ Data on frequency and duration of exclusive breastfeeding are available through large representative surveys like NFHS and DLHS while data on correct positioning and attachment are available through only few studies. So this study was conducted with the objective of assessing the correct positioning, attachment and effective suckling in infant breastfeeding as practiced by mothers.

\section{METHODS}

An observational, cross-sectional study was conducted in urban field practice area of a medical college in Central Gujarat from August 2015 to September 2015. We selected all 5 Anganwadis coming under this urban field practice area for the data collection. Assessment of breastfeeding practices was done on the day of Mamta Divas on the selected Anganwadis. Through the study period, we could observe the breastfeeding practices for 32 mothers whose children were less than 6 months of age.

One female paramedical worker from the department of community medicine was trained by the investigators to collect data and observe the infant's mouth attachment to breast, position of the child and effective suckling by using video clips and hands on training and demonstration in the hospital. Informed verbal consent was taken before data collection. Complete privacy was ensured while observing the feeding of the child. The female paramedical worker had observed the breastfeeding process for 5 minutes and record the mother and infant's positioning, attachment to the breast and effective suckling as per the standard IMNCI breastfeeding guidelines. ${ }^{4}$ It was done by asking the mother to put her infant to the breast, if the infant had not been fed in the previous hour. If the infant had been fed during the last 1 hour, then the mother was asked when the infant would have the next feed and the observation assessment was planned accordingly. If any mother refused to participate in the study next mother-infant unit was selected from the same Anganwadi. The other information like the age and weight of child, colostrum feeding, breastfeeding frequency was obtained using pretested questionnaire. After the assessment, if the paramedical worker would have found incorrect breastfeeding practices, she would explain the mother about correct practices with the help of photographs.

The collected data were compiled in Microsoft excel worksheet. Results were presented as percentage of number of mother-child units practicing proper positioning, attachment and effective suckling. The ethical clearance from the institutional Ethical Committee was obtained before conducting the study.

\section{RESULTS}

The study covered a total of 32 mothers for the assessment of breastfeeding. As per Table 1, one fifth of the infants assessed were less than two months of age while another set of two fifth of the infants were between 2-4 months of age. The rest two fifth of infants were 4- 6 months of age. Two third of the infants were having weight in range of 3-6 kgs.

Table 1: Characteristics of infants assessed $(\mathrm{N}=32)$.

\begin{tabular}{|ll|}
\hline Variables & No. $(\%)$ \\
\hline Age (months) & \\
\hline$<2$ & $6(18.75)$ \\
\hline $2-4$ & $14(43.75)$ \\
\hline $4-6$ & $12(37.5)$ \\
\hline Weight $(\mathrm{kg})$ & \\
\hline$<3$ & $3(9.38)$ \\
\hline $3-6$ & $19(59.37)$ \\
\hline$>6$ & $10(31.25)$ \\
\hline Colostrum given & \\
\hline Yes & $22(68.75)$ \\
\hline No & $10(31.25)$ \\
\hline Breastfeeding frequency (24 hrs) & \\
\hline$<8$ & $4(12.5)$ \\
\hline$\geq 8$ & $28(87.5)$ \\
\hline
\end{tabular}

Table 2: Assessment of breastfeeding practices.

\begin{tabular}{|ll|}
\hline Variables & No. $(\%)(\mathbf{N}=\mathbf{3 2})$ \\
\hline Assessment for proper attachment & \\
\hline Chin touching breast & $25(78.13)$ \\
\hline Lower lip turns outwards & $8(25)$ \\
\hline Mouth wide open & $25(78.13)$ \\
\hline $\begin{array}{l}\text { More areola visible above than } \\
\text { below the mouth }\end{array}$ & $14(43.75)$ \\
\hline Ability to attach & $0(0)$ \\
\hline No attachment at all & $30(93.75)$ \\
\hline Not well attached & $2(6.25)$ \\
\hline Good attachment & $22(68.75)$ \\
\hline Assessment for proper positioning & $25(78.13)$ \\
\hline Infant's head and body is straight & $26(81.25)$ \\
\hline $\begin{array}{l}\text { Baby is facing breast with infant's } \\
\text { nose opposite her nipple }\end{array}$ & $10(31.25)$ \\
\hline Infant's body is close to mother & $1(3.13)$ \\
\hline Infant's whole body is supported & $27(84.37)$ \\
\hline Positioning & $4(12.5)$ \\
\hline Poor (1 criteria met) & $2(6.25)$ \\
\hline Average (2,3 ) & $13(40.62)$ \\
\hline Good (all 4) & $17(53.13)$ \\
\hline Assessment of effective suckling & \\
\hline Not suckling at all & \\
\hline Not suckling effectively & \\
\hline Suckling effectively & \\
\hline
\end{tabular}


Almost two thirds of the mothers gave history of colostrum feeding. As high as $87 \%$ mothers were breastfeeding their infants 8 times or more per day.

Table 2 shows the findings of the breastfeeding assessment. Out of the criteria for correct attachment, only two children $(6.25 \%)$ fulfilled all 4 criteria which were classified as having 'good attachment'. Rest of the infants (94\%) were falling in the criteria of 'not well attached'. There were no infants classified in the category 'no attachment at all'.

The assessment for proper positioning revealed that only around $13 \%$ infants fulfilled all 4 criteria for good positioning. Majority $(85 \%)$ of the infants were having positioning classifiable in 'average' category with fulfilling two or three criteria out of the four. $53.13 \%$ of infants were suckling effectively. Another $40.62 \%$ were not suckling effectively.

\section{DISCUSSION}

The American Academy of Paediatrics Section on Breastfeeding recommends that "formal evaluation of breastfeeding, including observation of position, latch, and milk transfer should be undertaken by trained caregivers at least twice daily and fully documented in the record during each day in the hospital after birth". 5 Problems with the baby failing to latch, failing to latch properly, and/or problems with the mother's experience of breastfeeding pain are prevalent in the early postpartum period, and these problems contribute to breastfeeding discontinuation. ${ }^{6}$ Especially in young infants, positioning of infant for breastfeeding is important because poor positioning often results in poor attachment. Most difficulties can be avoided altogether if good attachment and positioning are achieved at the initial feeds. An effective sucking technique is also considered important to establish breastfeeding, to ensure milk transfer, and to prevent breastfeeding problems. The most common cause of pain during breastfeeding is due to nipple trauma caused by improper positioning and inappropriate latch-on.

In our study, out of the criteria for correct attachment only two children fulfilled all 4 criteria which were classified as having 'good attachment', rest of the infants (94\%) were falling in the criteria of 'not well attached'. The assessment for proper positioning revealed that only around $13 \%$ infants fulfilled all 4 criteria for good positioning. Majority ( $85 \%$ ) of the infants were having positioning classifiable in 'average' category with fulfilling two or three criteria out of the four. Almost half of infants were suckling effectively.

A study conducted in West Bengal by Prabha S, et al. reveal that good attachment and correct positioning were practiced by only $41.2 \%$ and $47 \%$ of mother-infant pairs respectively. ${ }^{7}$ Vandana $\mathrm{H}$, et al. from Karnataka in the year 2013 noted in her study that $65 \%$ of mothers with babies had correct position while feeding and about $56 \%$ of babies had correct attachment to their mothers. ${ }^{8}$ In a study done by S. Noor from Rourkela, $84 \%$ mothers had correct attachment of the babies while breastfeeding, but $72.9 \%$ were following incorrect practices regarding the position of the baby and about $87 \%$ mothers did not care much about their comfortable position while feeding their babies. ${ }^{9}$ Findings in a study done at rural Wardha show that significantly more mothers with feeding problems had problems in attachment to the breast as well as in positioning the infant to the breast. ${ }^{10}$

Although very well known to the scientific community, all these findings suggest that the correct breastfeeding practices are not followed by general population. Moreover with increasing nuclear families with urbanization there is hardly any sourse of information and/or support within the household for teaching a new mother the correct method for breastfeeding. Hence, there is a dire need to have programs educating mothers about the correct breastfeeding practices.

Limitation of the study was conducted with a small sample size within a limited period of time, so the study findings cannot be extrapolated to a large population.

\section{CONCLUSION}

We found from this study that the majority of infants fall in the 'average' grade, when we observed the breastfeeding practices like attachment and positioning. The staff of healthcare facility should be trained in specific knowledge and skills regarding breastfeeding practices and they should ensure education of the mothers regarding positioning and attachment of infant to the breast before discharge from the healthcare facility. In India, the ANMs are being trained in IMNCI strategy, which involves the training on positioning and attachment. So at the Village Health and Nutrition Day (Mamta Divas in Gujarat), their skills can be utilized for health education of future mothers and support for breastfeeding mothers.

Funding: No funding sources Conflict of interest: None declared

Ethical approval: The study was approved by the Institutional Ethics Committee

\section{REFERENCES}

1. World Health Organization. Global strategy for infant and young child feeding. Geneva: World Health Organization. 2003:41.

2. Gupta A, Dadhich JP, Suri S. Enhancing optimal infant feeding practices in India. India Health Beat. 2011;5(4).

3. Government of India, Ministry of Health and Family Welfare. Integrated management of neonatal and 
childhood illness: Training modules for medical officers. New Delhi: 2005.

4. WHO, UNICEF. Integrated management of neonatal and childhood illness. Physician Chart booklet Ministry of Health and Family Welfare Government of India. 2003.

5. Righard L, Alade MO. Effect of delivery room routines on success of first breast-feeds. Lancet. 1990;336:1105-7.

6. Cadwell K. Latching-on and suckling of the healthy term neonate: breastfeeding assessment. J Midwifery \& Women's Health. 2007;52(6):638-42.

7. Prabha S, Saha I. A study on feeding practice of under 6 months infants attending the nutrition clinic of a tertiary centre hospital of West Bengal, India. Epidemiology Biostatistics and Public Health. 2013;10(2).
8. Vandana H, Hemagiri K. Breastfeeding practices in Bellary, Karnataka: a hospital based study. J Pub Health Med Res. 2013;1(2):76-80.

9. Noor S, Hani RA. A Study on breastfeeding practices among mothers of urban slums of Rourkela. IOSR- J Dent Med Sci. 2015;14(5):77-80.

10. Dongre AR, Deshmukh PR, Rawool AP, Garg BS. Where and how breastfeeding promotion initiatives should focus its attention? A study from rural Wardha. Indian J Community Med. 2010;35:226-9.

Cite this article as: Davara K, Chavda P, Pandya C, Solanki D. Breastfeeding practices in children under 6 months of age: a community based study in urban field practice area of a medical college in central Gujarat, India. Int J Community Med Public Health 2016;3:1010-3. 